\title{
Food Security Challenges and Options in the Caribbean: Insights from a Scoping Review
}

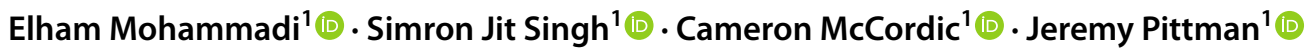

Received: 24 September 2021 / Revised: 14 December 2021 / Accepted: 15 December 2021 / Published online: 20 January 2022

(c) The Author(s), under exclusive license to Springer Nature Singapore Pte Ltd. 2022

\begin{abstract}
The Caribbean region remains susceptible to an increasing frequency of natural disasters, rising international debt, outmigration, rapid urbanization, and high imports to meet basic needs. Food and nutrition insecurity persists in these small island states, with around $67.5 \%$ of the population living in moderate or severe food insecurity. Policy adjustments required to address the targets subsumed by the second sustainable development goal (SDG2 or Zero Hunger) are still at an infant stage. This research offers rigorous and up-to-date analyzes of the current status of Caribbean food policies and practices through a scoping review and expert interviews to answer the question, "What constraints and enablers impact the ability of small island states to achieve the Zero Hunger goal?". A scoping review is performed following the relevant population, concept, and context (PCC) methodology by the Joanna Briggs Institute (JBI). Five major challenges and barriers are identified through the scoping review: (i) island geography, (ii) governance deficiencies, and (iii) institutional constraints, compounded by (iv) collaboration barriers, and (v) externally imposed impediments (including environmental and financial shocks). To address these challenges, synergistic linkages and restrictive connections have been recognized for SDG2 localization. It was concluded that three dimensions of food security (utilization, agency, and sustainability) are mainly overlooked, necessitating special attention and action. By identifying bridging institutions and engaging various actors in supporting shared rulemaking, power, conflict management, and knowledge-sharing among local, national, and regional policy actors, a polycentric governance system is recommended as a suitable mechanism to help islands move towards food security.
\end{abstract}

Keywords Food security $\cdot$ Food policy $\cdot$ SDG localization $\cdot$ Polycentric governance

\section{Introduction}

The global food system has faced ongoing sustainability challenges. According to the latest available reports, about $27.6 \%$ of the global population is living in moderate or severe food insecurity, and many countries still face persistent childhood stunting alongside rising rates of obesity (FAO 2021). Government policy has been recognized

Elham Mohammadi

elham.mohammadi@uwaterloo.ca

Simron Jit Singh

simron.singh@uwaterloo.ca

Cameron McCordic

c2mccordic@uwaterloo.ca

Jeremy Pittman

jpittman@uwaterloo.ca

1 Faculty of Environment, University of Waterloo, 200

University Ave West, Waterloo, ON N2L3G1, Canada as a crucial tool for the sustainable management of food systems and for ensuring a transition toward the United Nation's Zero Hunger goal (UN 2015). Candel and Daugbjerg (2020, p.174) define food policy as "a set of policy outputs adopted to address one or more food system activities with the explicit aim of affecting food system outcomes in the desired direction". Regulations, programs, plans, and other (semi-)legal items are examples of policy outputs that directly result from decision-making actions. The roots of modern food policy rely on the rise of productionism in the post-World Wars era as a solution to the food supply problem (Lang 1999; Lang et al. 2009). Food security is commonly defined by four pillars: availability, access, utilization, and stability, which have been expanded to include two additional dimensions: agency and sustainability (Clapp et al. 2021). These pillars play a major role in policy development. Traditionally, most food policies have been dedicated to food production and predominantly agriculture (Lang and Barling 2012); however, in recent years, different issues such 
as environment, health, trade, and innovation have also been incorporated into food policies (Lang and Heasman 2015).

Extreme weather events are negatively affecting food production and food availability in islands, requiring appropriate policies and legislation. These events are causing significant losses in agricultural production, necessitating the importation of food and the provision of financial aid (Ganpat and Isaac 2014, p. 13). Climate change impacts are even more acute in the Caribbean, requiring specific attention. For example, Dominica suffered a loss of US $\$ 1.3$ billion as a result of Hurricane Maria in 2017, accounting for 226\% of the national GDP, leading to a dramatic decline in fiscal performance and increasing external debt (IMF 2018). A recent regional comparison by International Monetary Fund (IMF) (2021) indicates that achieving sustainable development goals (including zero hunger) in SIDS directly correlates with building climate resilience (Tiedemann et al. 2021). However, additional costs are the largest in the Caribbean, compared to other SIDS, to increase resiliency and meet selected SDG targets (health, education, water, sanitation, and hygiene, energy, and roads) (ibid). The devastating impacts of climate change on food security are usually compounded by other challenges, such as shifting production practices, population growth, urbanization, new attitudes to diets, access to imported foods, price volatilities, deteriorating terms of trade, inefficient marketing practices, the shift towards a corporate food regime, a decline in conservation practices, more resource extraction, and an intensified "coastal squeeze" (Connell 2015).

Caribbean small island developing states (Fig. 1) have made significant adjustments in their governance of food systems (FAO 2015a). During the past 2 decades, several international and regional initiatives, policies, and action plans have been endorsed with the aim of ensuring food security (FS). They include but are not limited to the World Food Summit in 1996, Millennium Development Goals in 2000, Hunger-Free Latin America and the Caribbean Initiative (HFLACI) in 2005 (FAO 2017a), and Regional Food and Nutrition Security Policy (RFNSP) in 2010. Despite these efforts, the prevalence of moderate or severe food insecurity among persons remains high locally, at around $67.5 \%$ (in 2019), in contrast to the global average of $27.6 \%$ (FAO 2021).

FS challenges and policies in the Caribbean are being increasingly discussed as a matter of concern among several scholars, as well as among national and regional organizations. Pemberton and Harris (1988) performed one of the initial studies on the cheap-food policies in Trinidad and Tobago from 1973 to 1985 ; it showed that the financial resources transferred by these policies may or may not be used to buy more food by a different group of consumers. Since then, a number of studies have analyzed the impacts

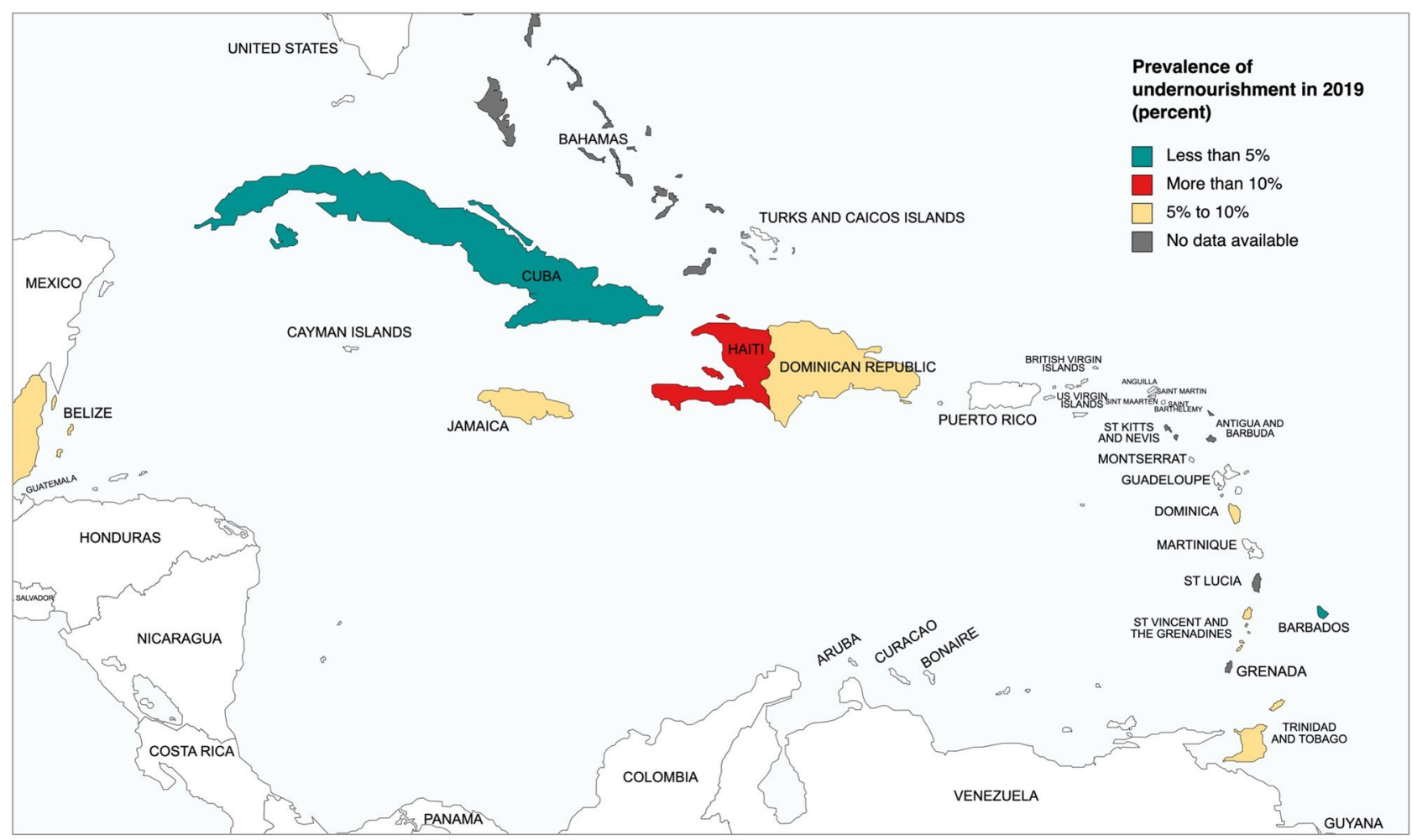

Fig. 1 A map of 14 Caribbean small island developing states (based on UN-OHRLLS 2011) and their prevalence of undernourishment (\%) 
of various policy options on food and nutrition security, such as the effects of economic policies (Henry 2012), agricultural policies (e.g., Grindle 1993; Kendall and Petracco 2009; Shik et al. 2017), and the effects of FS policies on their own (e.g., Lowitt et al. 2016; Wilson 2016; Saint Ville et al. 2017a; Mcpherson 2018). Furthermore, different theories and frameworks have been used to examine FS policy progress. For instance, Renwick (2013) used an Analytical Hierarchy Process (AHP) questionnaire to identify priorities of decision-makers, Lowitt et al. (2016) examined the level of food policy coherence to understand the synergies among the policies, and Saint Ville et al. (2017b) used "Stakeholder Analysis" to test the influence of policies on institutions. Some other studies and technical reports have also examined the contribution of different countries or stakeholders regarding the four dimensions of FS (e.g., FAO 2015a, b; Lowitt et al. 2016).

Despite various efforts for studying food security challenges and relevant policies in the Caribbean, barriers associated with the current policies and practices remain unclear, as are the required adjustments to fully address the second sustainable development goal (SDG2), Zero Hunger. To address this gap in the literature, this research analyzes the impact of myriad of food policies and practices in the Caribbean that are being applied to achieve FS. We ask: "What constraints and enables the ability of small island states to achieve the Zero Hunger goal?". To answer this question, we set four objectives: (1) Conduct a scoping review of previous food policy studies and identify the barriers to FS, (2) Identify and describe current best practices on sustainable FS in the Caribbean via interviews with local experts; then, given the findings from the first and second steps, (3) Discuss pathways to localization of SDG2 that urges local governments to be key implementation, and (4) Discuss key attributes of appropriate governance regimes for overcoming the identified restrictions or barriers.

\section{Methodology}

\subsection{Conducting a Scoping Review}

To address the first objective of the study and obtain a comprehensive view of the underlying barriers and challenges behind the high food insecurity rates in the Caribbean, the scoping review examined the region's studies relevant to food policies. A scoping review is a descriptive literature review technique by which researchers can rapidly capture major concepts and the underlying evidence for their topic of interest that underpin a study field (Mays et al. 2001). Such a review can be conducted as a stand-alone project, especially when the topic is complex or has not yet been studied comprehensively (ibid). The five stages of the framework by
Arksey and O'Malley (2005) were followed to perform this review; formulating the research question; identifying relevant studies; selecting appropriate studies; categorizing the data; organizing, summarizing, and reporting the findings. Then, the inclusion and exclusion were carried, considering the relevant population, concept, and context (PCC) mnemonic by the Joanna Briggs Methodology (JBI) (The Joanna Briggs Institute 2015). The PRISMA Extension for Scoping Reviews (PRISMA-ScR) was used as a reporting guideline (Tricco et al. 2018).

Following Arksey and O'Malley's framework (2005), as a first step, the research question was formulated: what are the barriers and challenges confronted with the fulfillment of the current FS policies in the Caribbean? Then, the relevant studies were selected to identify the underlying barriers and challenges to achieving FS. The papers were thoroughly studied, and the primary identified difficulties were outlined in each study. Similar themes were grouped together, and the resulting categories were named as seemed appropriate. The themes were then classified into two main categories. Finally, the frequency of each challenge and barrier were determined in the outlined documents.

The data collection process (Fig. 2) includes three major steps: initial assessment, screening, and selection. The literature was initially assessed in the Scopus digital bibliographical database. The Web of Science database was also assessed, but it did not include any form of subject headings. Keyword and Boolean search methods were applied to the database. Besides the food policy, other keywords, such as food governance and agriculture policy, were included in the query. Then, the resulting queries were made specific, using the terms Caribbean, CARICOM, and the names of the various Caribbean islands to search academic articles. Grey literature was retrieved by searching the websites of five international organizations: the UN Food and Agriculture Organization (FAO), the World Food Programme (WFP), the World Trade Organization (WTO), the International Fund for Agricultural Development (IFAD), and the World Bank. These organizations were selected by checking the reference lists of the selected articles. For the Scopus database, this initial search query was restricted to the titles, abstracts, and keywords of articles.

After screening 673 papers and removing duplications, 314 articles and reports were listed as the initial body of literature (Fig. 2). The inclusion and exclusion criteria were designed based on PCC mnemonic by the JBI (The Joanna Briggs Institute 2015). The population included were islands in the Caribbean, the concepts were the food and agriculture policy focusing on FS, and the context was current regional and national policy studies. The grey pieces of literature with a separate chapter on food or agriculture policy were also included in this review. On applying inclusion and exclusion criteria to the abstracts, titles, and keywords, 95 
Fig. 2 PRISMA diagram of database search, screening, and selection of articles

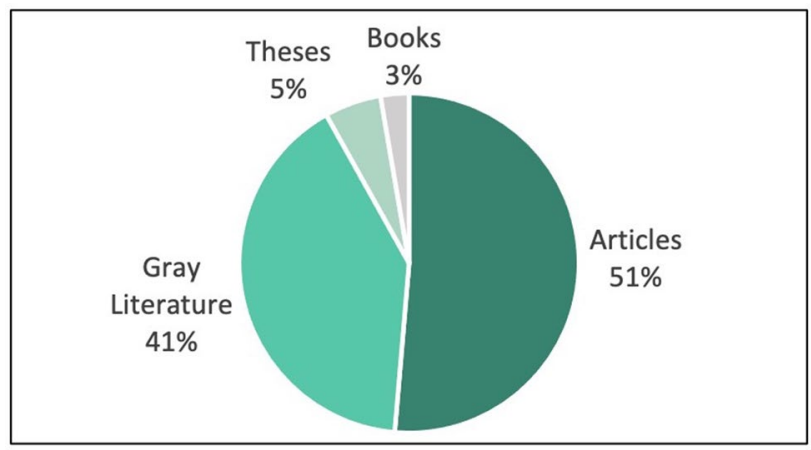

Fig. 3 Types of documents included in the scoping review

documents met the research criteria, and 57 were excluded because they did not explicitly report on the FS policies in the Caribbean islands. Two citations were excluded because the full texts were not accessible for further evaluation. This review identified 38 unique documents fulfilling our eligibility condition for addressing the review objective.

The included documents were dated between 1974 and 2019, with more than 53\% being from 2010 onwards, $21 \%$ from 2001 to 2010, and 26\% from 2000 and earlier. The most common document types (Fig. 3) were journal articles $(51 \%)$, followed by reports and working papers from
Initial assessment of the literature

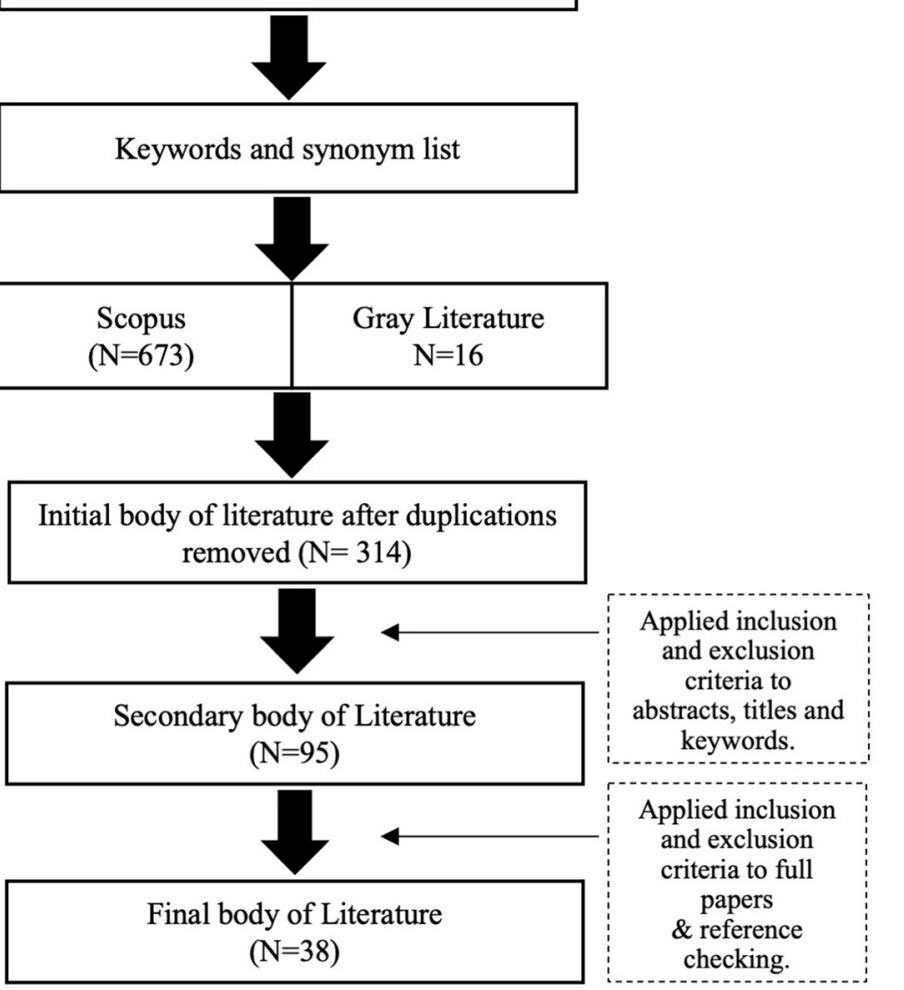

different organizations (41\%) such as the FAO and the Caribbean Development Bank (CDB). Predominantly, the researches considered one to four individual islands (53\%), and slightly fewer studies (47\%) were performed totally or partially Caribbean-wide.

\subsection{Interviews}

Following the scoping review, remote interviews with 12 informant stakeholders (Table 1) in the region were undertaken to identify best practices that address the underlying impediments and challenges. Six major stakeholder groups were targeted for the interviews: (1) researchers/academicians, (2) policymakers/decision-makers, (3) employees of ministries, (4) employees of international associations, (5) members of organizations founded by citizens (e.g., nongovernmental organizations or NGOs), and (6) others (e.g., entrepreneurs). The interviews were carried out in accordance with the designed interview protocol and were guided by the findings of the scoping review (which comprised questions based on the identified underlying barriers). The questions were chosen in accordance with the interviewee's area of expertise to better steer the discussion on how the best practices are applied from the interviewee's point of view. The interview notes were analyzed using content 
Table 1 The distribution of interviews among different countries and stakeholder groups

\begin{tabular}{|c|c|c|c|c|c|c|c|}
\hline \multirow[t]{2}{*}{ Islands } & \multicolumn{7}{|c|}{ Distribution of interviewees } \\
\hline & $\begin{array}{l}\text { Researchers/ } \\
\text { academicians }\end{array}$ & $\begin{array}{l}\text { Policymakers/ } \\
\text { decision-makers }\end{array}$ & $\begin{array}{l}\text { Employees of } \\
\text { ministries }\end{array}$ & $\begin{array}{l}\text { Employees of interna- } \\
\text { tional associations }\end{array}$ & $\begin{array}{l}\text { Members of } \\
\text { farmer associa- } \\
\text { tions }\end{array}$ & Entrepreneurs & Total \\
\hline Barbados & & 1 & & 1 & & & 2 \\
\hline Dominica & & & & 1 & 1 & & 2 \\
\hline Grenada & & 1 & 1 & & & & 2 \\
\hline Jamaica & & & 1 & 2 & & & 3 \\
\hline Trinidad \& Tobago & 1 & & & & & 1 & 2 \\
\hline Caribbean & & & & & 1 & & 1 \\
\hline Total & 1 & 2 & 2 & 4 & 2 & 1 & 12 \\
\hline
\end{tabular}

analysis to identify the frequency with which different themes were mentioned. Subsequently, best practices were further discussed on how they might impact achieving the SDG2.

\section{Results}

The scoping review findings and the recurring themes of challenges and barriers for achieving food security in the Caribbean are thoroughly discussed in this section. Then, interview findings and current best practices are described and compared with the results of scoping review.

\subsection{Scoping Review Results: Food Security Challenges and Barriers}

Eight recurring themes have emerged from the analysis of the food policy studies. Based on the recognized themes, FS challenges and barriers were categorized into two groups, as shown in Fig. 4: (1) direct policy deficiencies and (2) institutional constraints. Then, the frequency of each challenge and barrier was calculated in the outlined documents. It is worthwhile noting that the high frequency of a challenge or deficiency does not necessarily imply the significance of the issue. Conversely, the low frequency may only mean that the challenge has been acknowledged recently and has not been articulated yet in the literature.

As shown in Fig. 5, the majority of the documents mainly indicated two challenges in the region: lack of holistic/consistent approaches $(26 \%)$ and inefficiency in addressing vulnerability to shocks $(26 \%)$. Inequity in policies and practices (13\%) was the next frequent indicated issue. The next most recurring barrier was insufficient infrastructure (11\%), followed by inefficient knowledge exchange (9\%), and administrative obstacles (8\%). Finally, the least frequent themes in the documents were insufficient human capital (3\%) and top-down government initiatives $(3 \%)$. The identified challenges and barriers are directly related to the type of multi-level governance, the level of stakeholder engagement, policy alignment, and institutional capacity building, all of which are required for SDG localization. Each of these impediments is described below in more detail.

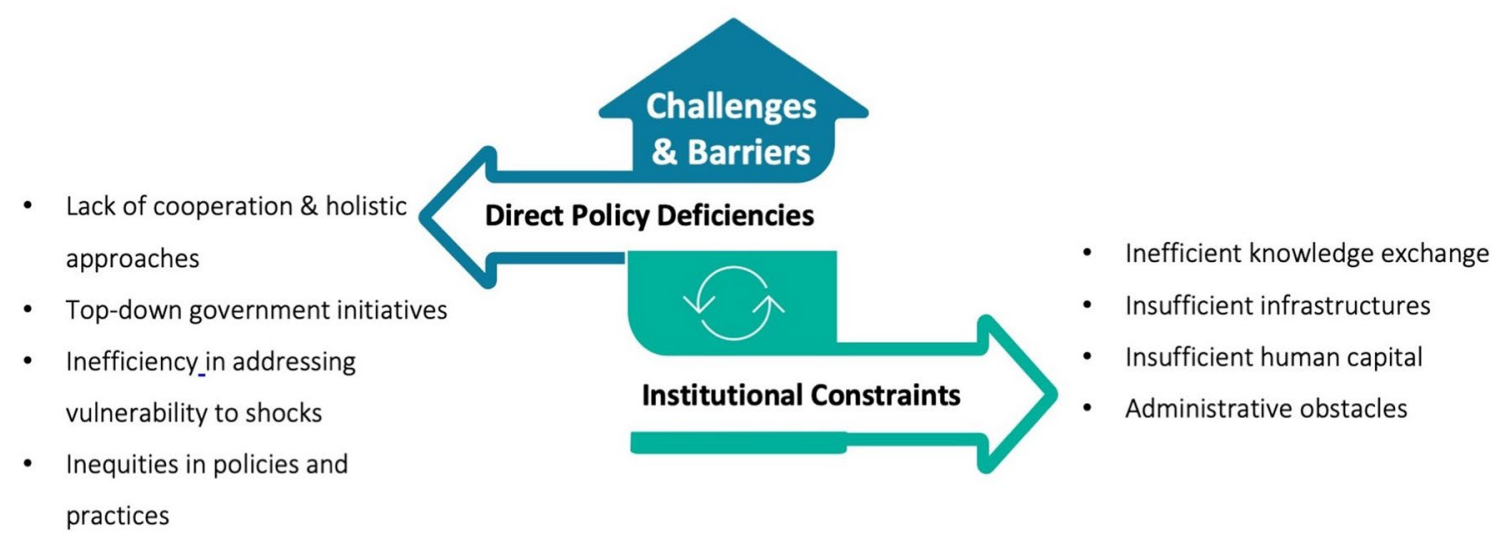

Fig. 4 Food security challenges and barriers based on the scoping review 


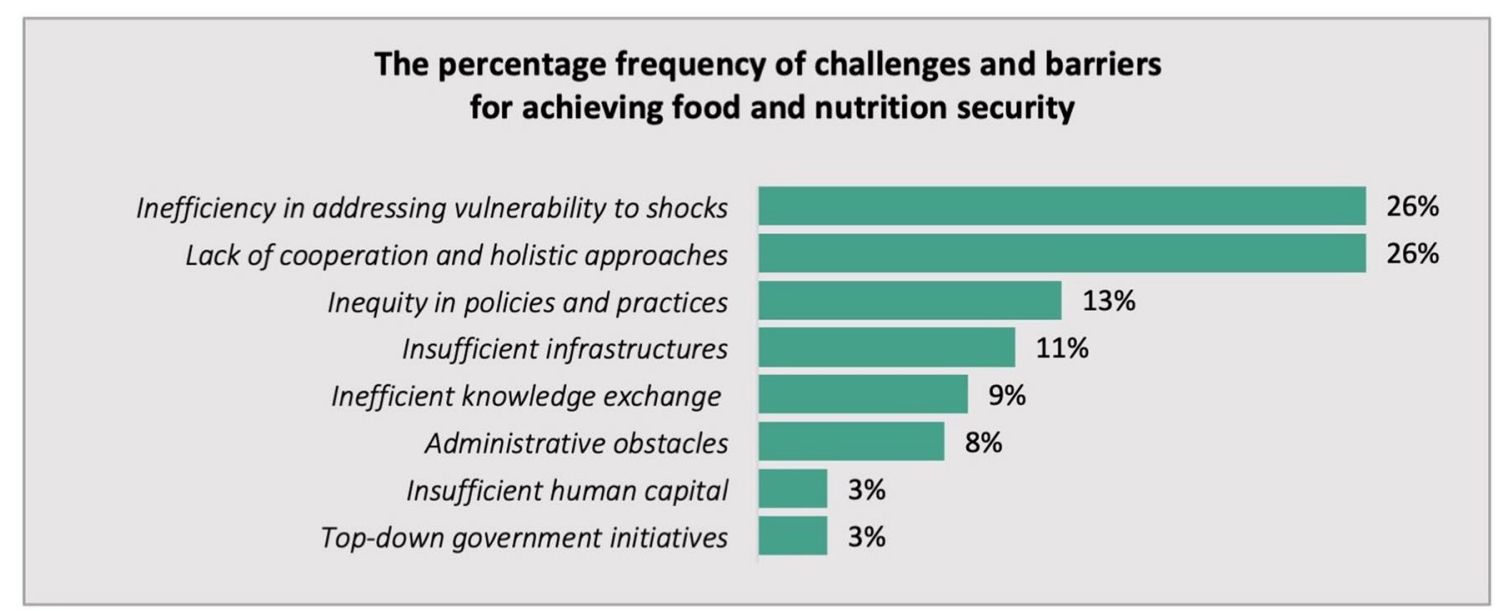

Fig. 5 The percentage frequency of challenges and barriers for achieving food and nutrition security based on food and agriculture studies

\subsubsection{Inefficiency in Addressing Vulnerability to Shocks}

Caribbean countries are classified as Small Islands with characteristics (e.g., smallness, isolation, fragmentation) that make them highly vulnerable to external shocks (FAO 2015b). Smallness, for example, causes diseconomies of scale in production, distribution, and administration, decreasing competitiveness and hindering diversification opportunities against shocks (IMF 2016). Besides structural limitations, environmental and economic vulnerabilities impede the ability of small islands to achieve sustainable development (Sachs et al. 2021). The Caribbean is prone to natural disasters, which often heat the islands and devastate the crops and the agriculture base (Henry 2012). Disasters negatively impact the social sectors (housing, settlements, health, education, and infrastructures) and economic sectors (e.g., agricultural, tourism, manufacturing, and commerce), all of which have an impact on food and nutrition security (FAO 2017b). Total economic damages and loss to the agricultural and food sectors from these disasters have been considerably high and show a rising trend (FAO and PAHO 2017). For instance, hurricane Maria (in 2017) cost Dominica 225 percent of its Gross Domestic Product (GDP) (The World Bank 2018), earthquake in Haiti (in 2010) cost $96 \%$ of GDP, and hurricane Ivan (in 2004) in Grenada cost $200 \%$ of GDP (IMF 2016). In small islands, catastrophic events affect nearly everyone, or nearly 100 percent of the population, whereas this is not the case in large mainland economies (Rahman et al. 2022).

Proactive approaches to address the climate changerelated challenges are lacking (e.g., McElroy and De Albuquerque 1990; Ford 1992; Dulal et al. 2009; Brown and Kyttä 2014; FAO and CDB 2019), and there is a significant need to broaden the agenda for agricultural and
FS policies to include more mitigation and adaptation options to counteract these threats (Trotman et al. 2009; Wilson 2016; FAO and PAHO 2017).

Besides the substantial economic impact of the environmental disasters, many studies have argued that heavy reliance on the global market for raw materials, intermediate goods, and final food produces have made the Caribbean islands extremely vulnerable to such shocks, including changes in international market prices (e.g., Cook and Yang 1974; Ahmed and Afroz 1996; Handa and King 1997; Canterbury 2007; Hawkes and Thow 2008; Kendall and Petracco 2009; Renwick 2013; FAO 2015b; Wilson 2016; FAO and CDB 2019). High dependence on unpredictable and unmanageable remote events for food supplies has been a long-term issue (Cook and Yang 1974). However, concerns over food have increased since the establishment of the World Trade Organization (WTO) in 1994 and the region's subsequent commitment to multilateral free trade (FAO, IFAD, UNICEF et al. 2019). The establishment of the WTO implied a termination to the preferential trades and exports from the Caribbean to the European Union (ibid). Ending these trade preferences resulted in a loss of market shares for major agricultural export commodities, the reduction of financial and resource inflows to the region, and a significant impact on the livelihood of people living in rural areas (ibid). Food imports to the Caribbean also increased significantly. For instance, the amount of food imported from the United States increased by $10 \%$ annually from 2004 to 2013 (USDA 2014). The growing import of food products and consumption of processed foods (FAO 2015a) have contributed to nutrition transition and increasing rates of non-communicable diseases (NCDs) in the region (Hawkes and Thow 2008). 


\subsubsection{Lack of Cooperation and Holistic Approaches}

To achieve FS in the Caribbean, many different regional and national policies have been proposed and implemented. However, Caribbean nations have yet to implement a holistic policy approach (Kendall and Petracco 2009; Harvey 2010; Brown 2014; Lowitt et al. 2016), and there have been only limited inter-sectoral collaborations among key stakeholders in the region (Brown 2014; Lowitt et al. 2016; Saint Ville et al. 2017b, a). There is also considerable divergence in how regional and local policy institutions frame and approach FS problems (Lowitt et al. 2016). Also, some aspects of FS are not well addressed in national and regional policies and procedures, including food safety (Grindle 1993; Kendall and Petracco 2009), as well as shipping and transport (Harvey 2010). Food safety is an increasingly significant regional concern as food-borne diseases (FBD) are on the rise in the Caribbean (FAO and CDB 2019).

A suite of efforts has happened in the region to increase food and nutrition security; however, these efforts have often focused on only a few parts of the system, neglecting the other aspects. For instance, in the Caribbean, an integrated assessment of the potential for mariculture is lacking. A study by Thomas et al. (2019) estimates the significant potential for mariculture in this region; the potential to produce cobia (a kind of marine fish) is estimated to be almost half the amount of seafood being harvested from wild fisheries across the world. In a recent study by Pittman et al. (2020), the relative performance of three different governance scenarios-"private-individual, community-based, and top-down governance"—are evaluated, highlighting the probable impacts of each scenario on the levels of conflict and development of fish aggregating devices (FADs). Freshwater aquaculture and "blue growth" can be the focus of research, policies, and investments (Belton et al. 2020). However, these initiatives require specific attention, policies and strategies, such as conservation policies for Marineprotected areas, to protect biodiversity, food provision, and carbon storage (Sala et al. 2021).

Food policy itself subsumes a myriad of influences on food system functions (Candel and Daugbjerg 2020). For instance, the structural adjustment programs (SAPs) in Jamaica during the late 1970s and early 1980s, which were designed to deal with the economic crisis, caused a high unemployment rate and increased health and food insecurity challenges (Henry 2012). Taking a comprehensive approach, the probable effects of other policies on the system should be assessed, especially for poor and marginalized communities (ibid). Shik et al. (2017) recommended that agricultural policy should use different instruments to concentrate on other subsectors. Achieving an integrated FS policy in the Caribbean requires national governments and regional institutions to employ their authority to support diverse stakeholders' participation and interaction in different food-related systems (Lowitt et al. 2016; Saint Ville et al. 2017b, a).

\subsubsection{Inequity in Policies and Practices}

Since the late twentieth century, scholars have raised the concern that women (FAO and CDB 2019) and small-scale farmers (McElroy and De Albuquerque 1990; Innerarity 1996) have unequal access to resources and the advantages of policies and programs within the food and agriculture system (Cook and Yang 1974; Pollard and Graham 1985; McElroy and De Albuquerque 1990; Brown 2014; Lowitt et al. 2016; Saint Ville et al. 2017b). A study by Pollard and Graham (1985) conducted an analysis on Jamaican food policy. They tried to test the argument of the populist government of Michael Manley (1972-1980) on the progress of programs designed to promote equity and efficiency among agricultural producers. According to this research, the government programs did not increase equity within the agricultural sector, and land distribution became more concentrated. In 2019, a report by FAO and CDB revealed that gender inequality is a "major concern" in the Caribbean, with women accounting for only approximately $22-30 \%$ of the region's registered farmers. Women face fewer opportunities in agriculture due to limited access to funding, land, information, networks, and decision-making opportunities (FAO and CDB 2019).

In 1974, Cook and Yang stated that it is hard for small manufacturers (e.g., small-scale farmers) in the Caribbean to compete with large global companies. Later, in 1990, McElroy and De Albuquerque (1990) identified that agricultural policy favoured large-scale export farming over small-scale local farming. Brown (2014) studied the experiences of traditional farmers in Western Jamaica and examined the connections between smallholder farmers and the political economy. A longitudinal study was performed with the conceptual grounding theory of social construction and using the sectoral Parliamentary discourse. It was claimed that a bottom-up approach to policies is required to incorporate a reasonable understanding of smallholder farmers. Saint Ville et al. (2017a) argued that rule convergence in formal and informal agricultural production systems relegated informal bodies to a lower position in the institutional hierarchy. McPherson (2018) studied FS in Cuba and recommended that a new political economy is needed, including food policy networks that pay attention to the needs of non-state producers and consumers, giving genuine decision-making powers in policy-making and resource allocation to non-state producers (Mcpherson 2018). 


\subsubsection{Insufficient Physical Infrastructures}

Previous studies have stressed the need to focus on the infrastructure required for an effective transition towards FS in the Caribbean. Some of the challenges that islanders face include lack of transportation infrastructure (Kendall and Petracco 2009), inadequate irrigation systems (Singh et al. 2005; Kendall and Petracco 2009), limited access to information and communications technology (ICT) systems (Brown 2014), and skewed allocation of lands (Kendall and Petracco 2009). According to Singh et al. (2005), while some farmers in use enhanced irrigation methods (mostly drip irrigation), the efficiency and maintenance of these systems must be updated and improved. Tirado et al. (2016) argued that improving access to water and sanitation be prioritized in these countries. The land management system is complicated in many islands, with legitimate but informal tenure of unregistered family lands and illegal possession of state or private lands (FAO and CDB 2019). It has been argued that investments in infrastructure can reduce total production costs and have a long-term influence on competitiveness (Derlagen et al. 2017).

\subsubsection{Inefficient Knowledge Exchange}

Knowledge exchange and learning should be enhanced in the food system and policy network (Saint Ville et al. 2017b). The impacts of the various FS programs cannot be assessed without effective monitoring and evaluation (e.g., Derlagen et al. 2017; FAO and CDB 2019). Tirado et al. (2016) argued that due to the lack of data on allocating human and financial resources to nutrition programs, developing an effective nutrition policy is challenging. Data are gathered and but not effectively aggregated over different structures to evaluate the impacts. In Guyana, for instance, the Ministry of Agriculture's decentralized structure has resulted in insufficient, inconsistent, and widely dispersed data (Derlagen et al. 2017). It has been suggested that policies are needed to put in place systems and technologies for collecting and tracking data (Harvey 2010) on food-borne diseases (FAO and CDB 2019), allocation of resources (Tirado et al. 2016), production of crops, projected yields, harvested schedules, quality, and prices (Harvey 2010).

\subsubsection{Administrative Obstacles}

Several administrative obstacles limit the possibility of progress towards FS in the region, including business development constraints (FAO and CDB 2019), lack of supportive conditions for multi-stakeholder processes (Saint Ville et al. 2017b), trade barriers, inadequacies in extension services, and ineffective marketing (Kendall and Petracco 2009). Caribbean economies ranked 124 on average (for 2018) in terms of the ease of doing business (ranks countries from 1 to 190, with first-place being the best), and the main business development constraints are recognized as getting credit, registering properties, and obtaining construction permits (FAO and CDB 2019). In Jamaica, for instance, affordable credit or insurance programs for small-scale farmers are limited, although this group frequently requires assistance when crops are destroyed by natural disasters or diseases (Brown 2014). Lack of supportive conditions for multi-stakeholder practices is another concern. Saint Ville et al. (2017c) explored the nature of the stakeholder interactions surrounding the development of Saint Lucia's National Agricultural Policy and revealed a lack of supportive conditions for effective multi-stakeholder processes (Saint Ville et al. 2017b). Caribbean FS is also subject to trade barriers that have damaging impacts on the international competitiveness of local producers (CARICOM 2011). Non-tariff measures (NTMs) in CARICOM are regulated, monitored, and enforced in a relatively underdeveloped manner (ibid). Furthermore, CARICOM countries face challenges in meeting international standards and NTMs, which restricts their ability to compete in global markets (ibid). This incapacity to compete has been compounded by inefficient marketing techniques (Kendall and Petracco 2009).

\subsubsection{Human Capital Constraints}

In the Caribbean, human systems' ability to respond to food and nutrition insecurity is considered to be limited (Cook and Yang 1974; Kendall and Petracco 2009; FAO and CDB 2019), emphasizing the importance of human capital development and protection (FAO and CDB 2019). The food system encounters a set of labour-related concerns, including seasonality, remoteness, poor working conditions, and value chain complexities (FAO 2019). In 1992, Ford stated that food insecurity had been linked to a remarkable migration rate in Guyana, caused by loss of human capital. Therefore, food unavailability was recognized to be associated with significant rates of migration. Saint Ville et al. (2017b) highlighted that the shift of labour and land resources to exportoriented food production had negatively impacted domestic fresh food production volumes and supply consistency. To tackle these labour-related challenges, the need for a proper human capital development strategy is emphasized.

\subsubsection{Top-Down Government Initiatives}

The top-down approach has been critiqued as it relies on only a few people reaching shared food policy goals and encourages only minimal participation from civil society groups, informal institutions, and the private sector (Lowitt et al. 2016; Saint Ville et al. 2017b). In Saint Lucia, for example, there is a need to identify bridging institutions 
in the domestic agri-food industry that could foster shared rulemaking, power decentralization, and knowledge sharing among political bodies (Saint Ville et al. 2017b). It has been suggested that top-down implementation of FS targets would have to be replaced by a cooperative approach in which all players undertake the responsibility to achieve agreed-on policy objectives (Lowitt et al. 2016). Food sovereignty has also been proposed as a critical response. In 2007, a group of delegates from several local farmer organizations submitted an Agricultural Manifesto to CARICOM (Thompson 2019). The Manifesto was based on food sovereignty principles, urging "bottom-up solutions" and "participation" over "consultation" (ibid). However, implementing sovereignty, which would allow local decisions to be made independently of global capital's dictates, continues to be one of the region's most pressing concerns (ibid).

\subsection{Interview Results: Beneficial Practices for the Caribbean}

The interview analysis allowed for a better understanding of expert perspectives on previously implemented or ongoing best practices of FS approaches in the region. Over the years, there have been scattered efforts throughout the Caribbean to achieve food and nutrition security. These best practices were categorized under the eight impediment themes identified in the scoping review. Figure 6 summarizes the number of times interviewees touched on material related to the various theme. Best practices targeting vulnerability to external shocks were recalled most frequently. However, programs or policies aimed at bottom-up decision-making (including potential contributions from all concerned) were mentioned only rarely. Further details on interviewees' perspectives on each theme are given below.

\subsubsection{Addressing Vulnerability to Shocks}

In terms of availability, food is available throughout the Caribbean, mainly from importation. However, vulnerability to economic and external shocks, such as the recent COVID-19 pandemic, can impact food availability and people's access to food. The best practices participants suggested for reducing vulnerability to external shocks can be classified into three main categories: building up self-sufficiency in agricultural production, implementing climate-smart systems, and developing policies and plans.

Improving local production was identified as one of the most critical implemented practices. The region largely imports its food needs, and there is a sort of rolling pipeline of food with as little storage as possible in each of the countries. Most interviewees mentioned that the pandemic had highlighted the importance of local production when the risk of border closure is increased. Many concerns were voiced about potential interruptions of trade (such as the closure of production facilities in the US as a major supplier, restricted food trade policies, and restrictions in transportation system), and governments expressed grave concern that they would not have enough food on the islands to feed their people under COVID-19 restrictions. Several governments responded by providing seeds and tools to more marginalized populations (for instance, in Grenada). Therefore, many people have begun backyard gardening or home gardening, and agriculture has become popular.

Pre-COVID-19 pandemic, various efforts had been made throughout the years to achieve agricultural self-sufficiency, ranging from developing local production and productivity to diversifying goods and strengthening agro-processing capacities. For instance, Interviewee 10, from Dominica, stated:

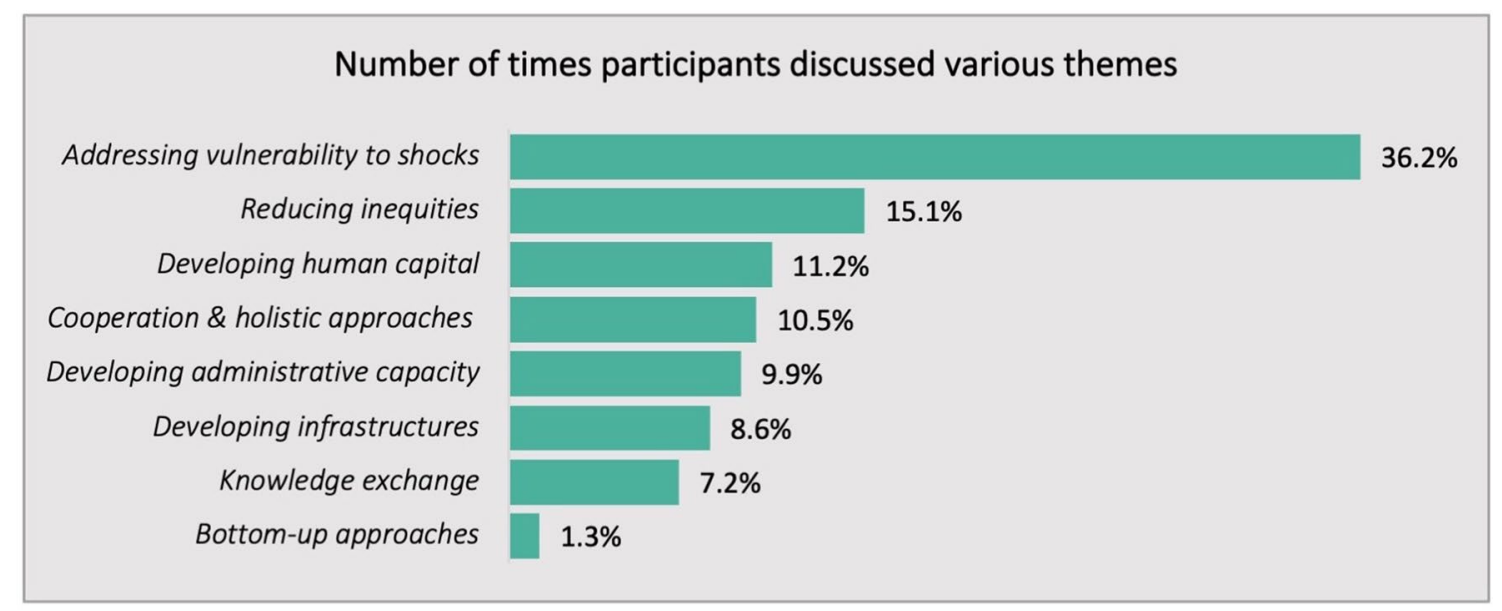

Fig. 6 Number of times participants discussed various types of efforts to overcome challenges to achieving food and nutrition insecurity 
A much wider diversification program has been initiated, and some progress has been made in terms of root crops and fishing. A wider range of root crops is produced now, such as yams and eddoes.

Or Interviewee 6, from Barbados, mentioned:

Over the last 50 years, agricultural productivity has led to about a threefold increase in output; it has [been] done with $76 \%$ less labour and $28 \%$ less land.

Agricultural development is hampered by islands' small size and remoteness, with little to no opportunity for economies of scale and competitive advantage. Tariffs and price control systems were recognized as successful tools to achieve self-sufficiency. For the meat and poultry industries, the countries in the region tend to have very high tariff rates because these industries cannot compete with larger international companies due to economies of scale. Some countries also have a price system regulated by the government to ensure access to food. For instance, the price of sugar and flour in Grenada is controlled by the government. In addition, other systems are in place to control the food situation, as highlighted by interviewee 11:

There's also the Grenada Cooperative Nutmeg Association (GCNA). And this organization, basically, is the central unit when it comes to trading. So, let's say I grow nutmeg. I cannot just decide I'm going to export. I would have to sell my nutmeg to GCNA, and then they would export it.

Different mitigation and adaptation practices for climate change were highlighted as being successful such as water harvesting technologies, drip irrigation systems, small-scale fertigation systems, mulch technologies, and developing climate-resilient varieties of crops (that can withstand flooding, salt tolerance, droughts, and hurricanes). In Barbados, the Intra-ACP Agricultural Policy Programme (Intra-ACP APP) was said to be one of the most significant Caribbean Agricultural Research \& Development Institute (CARDI) projects focusing on climate resilience and mitigation. This initiative was a comprehensive technical cooperation framework focused on the Caribbean and the Pacific to assist African, Caribbean, and Pacific (ACP) countries in eradicating poverty (INTRA-ACP APP n.d.). The Essex Valley agricultural development project in Jamaica was indicated to be another significant effort meant to alleviate farmers' water-related problems. Considering the location of some islands (e.g., Dominica is located within the annual Atlantic hurricane path), "mitigation is not that simple if and when extreme weather events occur", as Interviewee 3 states.

\subsubsection{Reducing Inequity}

Several programs have been implemented to enhance the participation of small-scale farmers, women, and youth in the food and agriculture system as a means of reducing inequity. During the interviews, various farm-level support programs were highlighted by interviewees, such as the Farmer Enfranchisement \& Empowerment Programme (FEED) in Barbados, which is aimed at reducing agricultural imports and increasing employment, particularly among vulnerable groups (including you and women) in the agriculture sector. Caribbean Agricultural Research \& Development Institute (CARDI) projects, instead of just being demonstrated at official training stations, were recognized as encouraging small farmers to establish best practices for their own farms. Buyback programs were additionally recognized to be beneficial, as Interviewee 8 (from Jamaica) put it:

The government has a program where they buy agricultural produce from the small farmers and [sell it] in the farmers market and in town centers across the country, and a lot of small farmers benefit from this.

Two projects were highlighted by interviewees as addressing the unique needs of women in the Caribbean: a joint UN program launched in 2020 that focuses on women and youth empowerment in agriculture and a buyback program launched by FAO during the COVID-19 pandemic targets women. However, both plans are new and have not proven successful yet.

\subsubsection{Developing Human Capital}

Human resource development in the region has primarily taken the form of education programs that have targeted (1) students, (2), farmers, and (3) training professionals in higher education. School gardening in primary schools and capacity building for farmers through training seminars, workshops, and other programs are done by national and international organizations. For instance, in Trinidad \& Tobago, FAO and the Inter-American Institute for Cooperation on Agriculture (IICA) have webinars on the packaging, post-harvest technologies, and minimizing waste on farms. The Agriculture Department at the University of West Indies and the Guyana School of Agriculture were indicated as strong examples dealing with training and capacity building in human resource development as it relates to FS. Other projects in the region also include onthe-job training. To summarize Interviewee 2 (in Barbados), under the coconut project, scientists have been sent to other countries to learn technologies in tissue culture; then farmers, lab technicians, and scientists collaborate to share the knowledge. 


\subsubsection{Implementing Cooperative and Holistic Approaches}

During the interviews, stakeholders highlighted the importance of intra-regional cooperation and collaboration. The key initiatives and best practices listed can be divided into two main categories: (1) establishing organizations and (2) establishing joint programs and agreements. The Caribbean Community (CARICOM), the Organisation of Eastern Caribbean States (OECS), AGRICOM, and the Caribbean Agricultural Research \& Development Institute (CARDI), were the four organizations pointed out as successful establishments. Intra-regional agreements on trading between islands were noted to be quite significant. For instance, Interviewee 5 stated that Dominica is the food basket of the Caribbean and provides a considerable amount of food to Antigua, St. Kitts, and other islands. He also added that Dominica buys coconut products from St. Lucia and other countries for processing. Interviewee 6 stated that recently Barbados and Suriname had signed the Brokopondo agreement to strengthen business relations between the two countries. Other than trading efforts, a handful of programs were mentioned for capacity building and technology transfer, such as the program by CARDI that involves several Caribbean countries, named Alliances for Coconut Industry Development, Expansion, and Enhanced Support for the Caribbean.

\subsubsection{Developing Administrative Capacity}

Interviewees highlighted a range of practices aimed at reducing business constraints, seeking to develop administrative capacity. The stated efforts can be clustered around three theme areas: (1) giving land tenure rights, (2) providing financial supports, and (3) developing business expansion opportunities. Land tenure is probably one of the most significant disincentives of the agriculture sector in some Caribbean countries such as Jamaica and Trinidad and Tobago. Interviewee 1 noted that the government of Trinidad and Tobago had made significant efforts to give farmers leases or titles to lands during the past 5 years. For instance, when the sugarcane industry in Trinidad and Tobago closed down, large landmasses were available for use. The government decided to block 2 acres of land and make it exclusively available to farmers. Employees of the national sugar company in Trinidad and Tobago got first access to the land, followed by the former sugarcane farmers. The idea was to convert the land to productive cropland to produce any crops other than sugarcane [Interviewee 2, Trinidad and Tobago].

Based on interviews, various attempts to give loans/ financing to farmers have been made in the region. Financial institutions, such as the Agricultural Development Bank in Trinidad and Tobago and the Development Bank of Jamaica, have also been stated by participants as organizations that provide financial services to the agriculture sector. Aside from financial services, few programs are assisting small businesses in getting started and expanding. One-stop shops were set in Jamaica to facilitate the company registration and trade licensing processes [Interviewee 9, Jamaica]. Additionally, Interviewee 9 adds:

...in terms of financing, [and in terms of land divestment] I go back to the PIP, which is the Production Incentive Program, where farmers are provided with inputs, fertilizers, and chemicals at a lower cost.

\subsubsection{Developing Infrastructure}

According to participants, in terms of infrastructural development, the region has made sporadic efforts. Interviewees provided some examples of the development practices, including improving irrigation systems (in Barbados), seed storage facility (in Jamaica and Trinidad and Tobago), plant breeding and genetics systems (in Trinidad and Tobago), storage facilities (in Jamaica), cold storages (in Grenada and Jamaica), fishing equipment (in Dominica), agro-parks (in Jamaica), and agro-processing centers (in Dominica). Due to the importance of seeds for FS, Interviewee 2 signified the Bodles seed storage facility, funded by the Pilot Program for Climate Resilience (PPCR) Project, as a significant initiative in Trinidad and Tobago.

\subsubsection{Improving Communication and Knowledge Exchange}

Based on the interviews, data collection is currently carried out in two main levels: (1) data on food and agriculture production and pricing, (2) data on imports. Participants acknowledged some unique data gathering practices in the region: the Agricultural Business Information System (ABIS) by Jamaica, the GIS technology system for the banana sector in Jamaica, and the record-keeping app by Inter-American Institute for Cooperation on Agriculture (IICA) used in Trinidad and Tobago. Interviewee 2 highlighted, certain initiatives are being taken to improve national and regional data collection, but currently, they are not in the best state. For instance, most countries collect data through a general census every ten years or so but do not have an agricultural census. The participant also added that the FAO website contains data at the national level for Caribbean countries, but it is uncertain whether some of the data is accurate. For e.g., for a particular year, FAO reported about 500 sheep for Trinidad, a meagre figure and was most likely not representative of the actual figure.

\subsubsection{Improving Bottom-Up Approaches}

Given the complexity of the UN's SDGs, including SDG2, there is a growing desire for bottom-up governance methods 
by helping governments and individuals in establishing relationships to make progress on the localization of the 2030 Agenda (Bonsu et al. 2020). Despite the importance of bottom-up governance mechanisms, there were only isolated mentions (by one participant only) of a point on improving such approaches. Interviewee 8 highlighted the role of the Jamaica Agricultural Society, the largest farmer organization in the Caribbean, with over 100 years of history. The importance of this organization was recognized for providing advocacy and lobby for the benefit of the farmers.

\subsection{Result of the Scoping Review Versus Interviews}

Figure 7 compares the percentage frequency distribution of observing each theme in the scoping review versus interviews. It shows that some themes were observed more frequently in expert interviews than scoping review, such as those targeted at reducing vulnerability to environmental and economic shocks. Some others-such as developing bottom-up approaches, enhancing knowledge exchange, developing infrastructures, and enhancing cooperative and holistic approaches-appeared less in the interviewees than in the review. It can be presumed that the underlying issues of the latter themes will require additional attention in future initiatives. However, further evaluations would be required to explore in detail the effectiveness of the best practices.

\section{Discussion}

According to our review of the literature and best practices in the Caribbean, the causes of food and nutrition insecurity are rooted in deficiencies and barriers at three different system levels: intra-, inter-, and extra-island systems (Fig. 8). Major intra-island shortcomings are island geography, governance deficiencies, and institutional constraints compounded by inter-island collaboration barriers and externally imposed impediments. The characteristic barriers of small islands include boundedness, smallness, isolation, and fragmentation (Baldacchino and Wivel 2020). These characteristics restrict islands' economies of scale and production competence. Governance deficiencies-including lack of cooperation and holistic approaches, top-down government initiatives, inefficiency in addressing vulnerability to shocks, and inequities in policies and practices — can adversely affect food and nutrition security. Other intra-island impediments are institutional constraints, including inefficient knowledge exchange, lack of infrastructures, and insufficient human capital, and inadequate administrative capacities. At the extra-island level, environmental and economic vulnerabilities are some of the externally imposed barriers that impede the ability of small islands to achieve FS.

Food and nutrition insecurity at different levels is triggered by different causes and requires solutions reflecting these complexities (Klennert 2005). Identifying the synergies and trade-offs between SDGs helps to identify transformation pathways (UCLG 2019). Localization of SDG2 would help governments with re-interpretation/re-defining of the SDG targets, policy development, implementation,

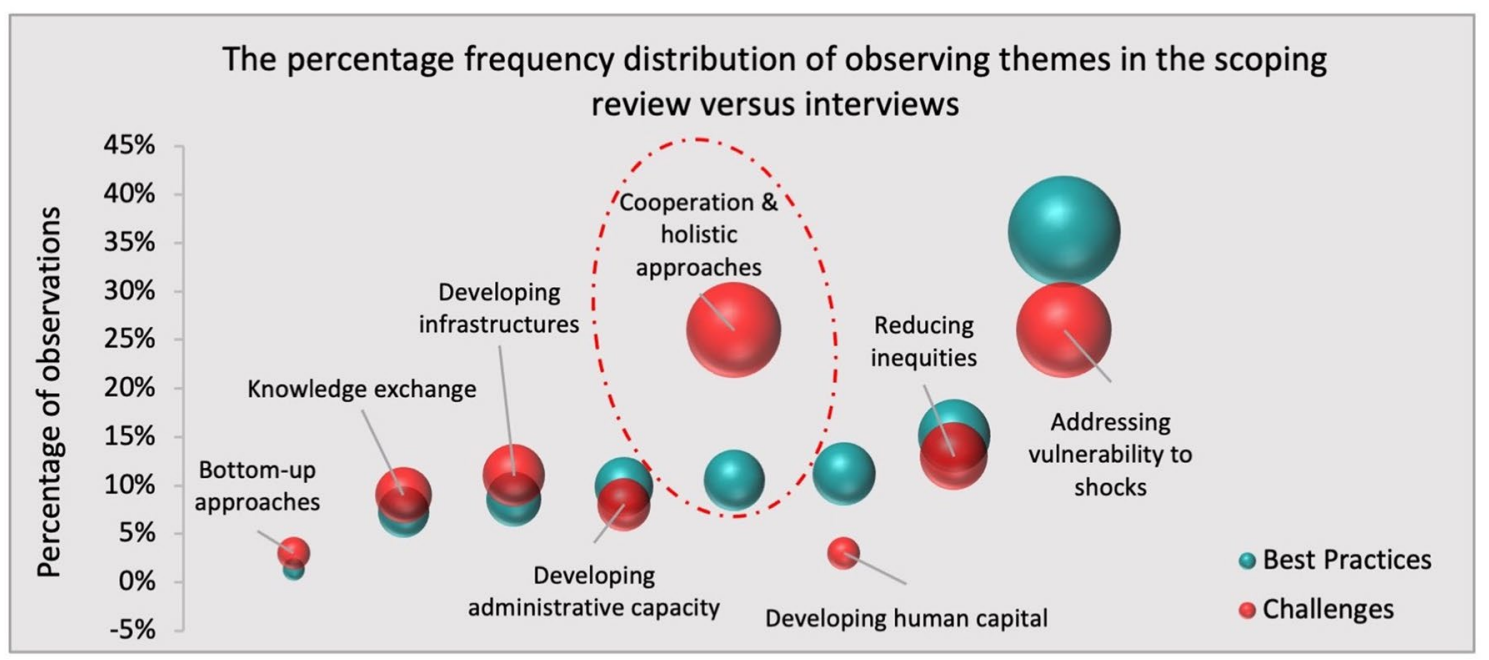

Fig. 7 The percentage frequency distribution of observing themes based on challenges and barriers identified in the scoping review (in red) versus the number of times participants discussed best practices (in green). (Lack of cooperation and holistic approaches were identi- fied as one of the primary concerns to achieving food and nutrition security in the scoping review. However, efforts to improve these approaches appeared far less in the interviewees) 
Fig. 8 Major causes of food and nutrition insecurity on small islands

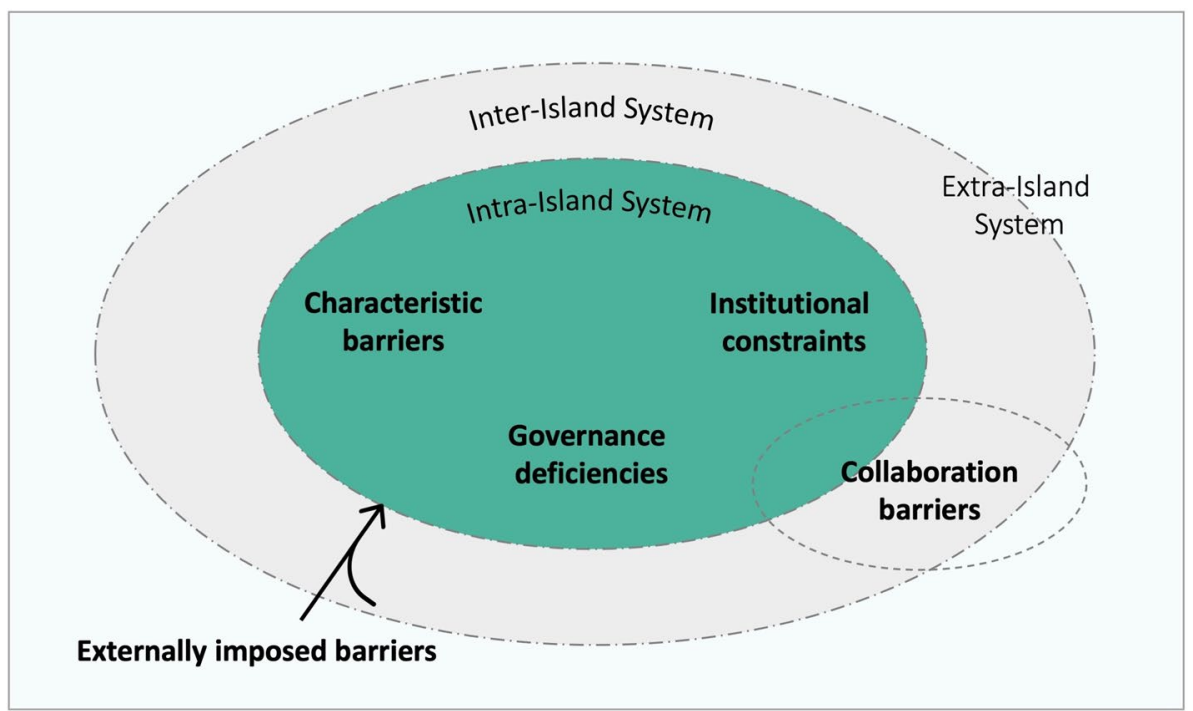

and monitoring (Slack 2014). SDG localization would generally include policy and governance approach alignment, stakeholder engagement, community-based project implementation, and monitoring (ibid). Based on the information from expert interviews and scoping review, we identified the interactions between SDG2 and other SDGs in an island context. Our case highlighted significant trade-offs between SDG2 and the other eleven SDGs; among which ten positive (synergies + ) and two negative interactions (trade-offs -) are observed (Table 2). The interconnections present both substantial potential and challenges for enhancing synergistic interactions (as enablers) while avoiding constraining connections. These synergies and trade-offs can mainly be categorized into three dimensions:

(i) Socio-economic: SDG1 (no poverty), SDG3 (good health and well-being), SDG4 (quality education), SDG 5 (gender equality), SDG 10 (reduced inequalities).

(ii) Environmental: SDG 6 (clean water and sanitation), SDG 13 (climate action).

(iii) Developmental: SDG 9 (industry, innovation, and infrastructure), SDG 11 (sustainable cities and communities), SDG 12 (responsible consumption and production), SDG 16 (peace, justice, and strong institutions), SDG 17 (strengthening global partnerships).

Taking an inclusive and holistic approach, the potential trade-offs and interactions of policies and plans on subsystems should be assessed prior to the implementation. However, due to several factors, such as lack of bottom-up approaches, inadequate stakeholder engagement, and ineffective knowledge exchange, such plans have yet to be implemented. According to Interviewee 7, FAO launched a program in Jamaica during the COVID-19 pandemic, targeting women, with the first focus being to buy back agricultural products from them. However, a significant number of females were left out of the program, as they were mainly in the small-scale livestock sector, and the program did not have the infrastructure to buy, store, and transport chicken and meat. Such debatable plans emphasize the significance of bottom-up processes, in which local needs, priorities, and expectations frame policies and strategies.

Only three of the six dimensions of food and nutrition security, namely availability, accessibility, and stability, are primarily addressed by current practices. The other three dimensions (utilization, agency, and sustainability) necessitate special attention and action. The increasing prevalence of malnutrition is a significant concern in the Caribbean (highlighting the importance of focusing on utilization), causing concerning levels of non-communicable chronic diseases (NCDs) (Jamaican Ministry of Agriculture and Fisheries and Ministry of Health 2013; Molina Barrera et al. 2018). The cause of this rising trend is a shift in diet from traditional foods to processed, high-calorie, and nutritionally deficient foods, a problem that must be addressed in future efforts. Agency is another major concern. There is a growing call, in academia, for bottom-up governance practices in achieving sustainable development goals (Bonsu et al. 2020). Nevertheless, our interview results show that such practices are scarce in the Caribbean food system. Furthermore, there is a dearth of policies and initiatives to ensure sustainable food systems that can achieve and sustain food and nutrition security for current and future generations and meet social, environmental, and economic demands and protect the integrity of the processes.

To address deficiencies in the current system, there is a need to identify bridging institutions at local, national, and regional levels and to engage multiple actors in 
Table 2 Synergies and trade-offs between Zero Hunger and other SDGs in the Caribbean (the degree of potential synergies and trade-offs among the SDGs may vary based on different factors, including, inter alia, available resources, development phase, and policy responses)

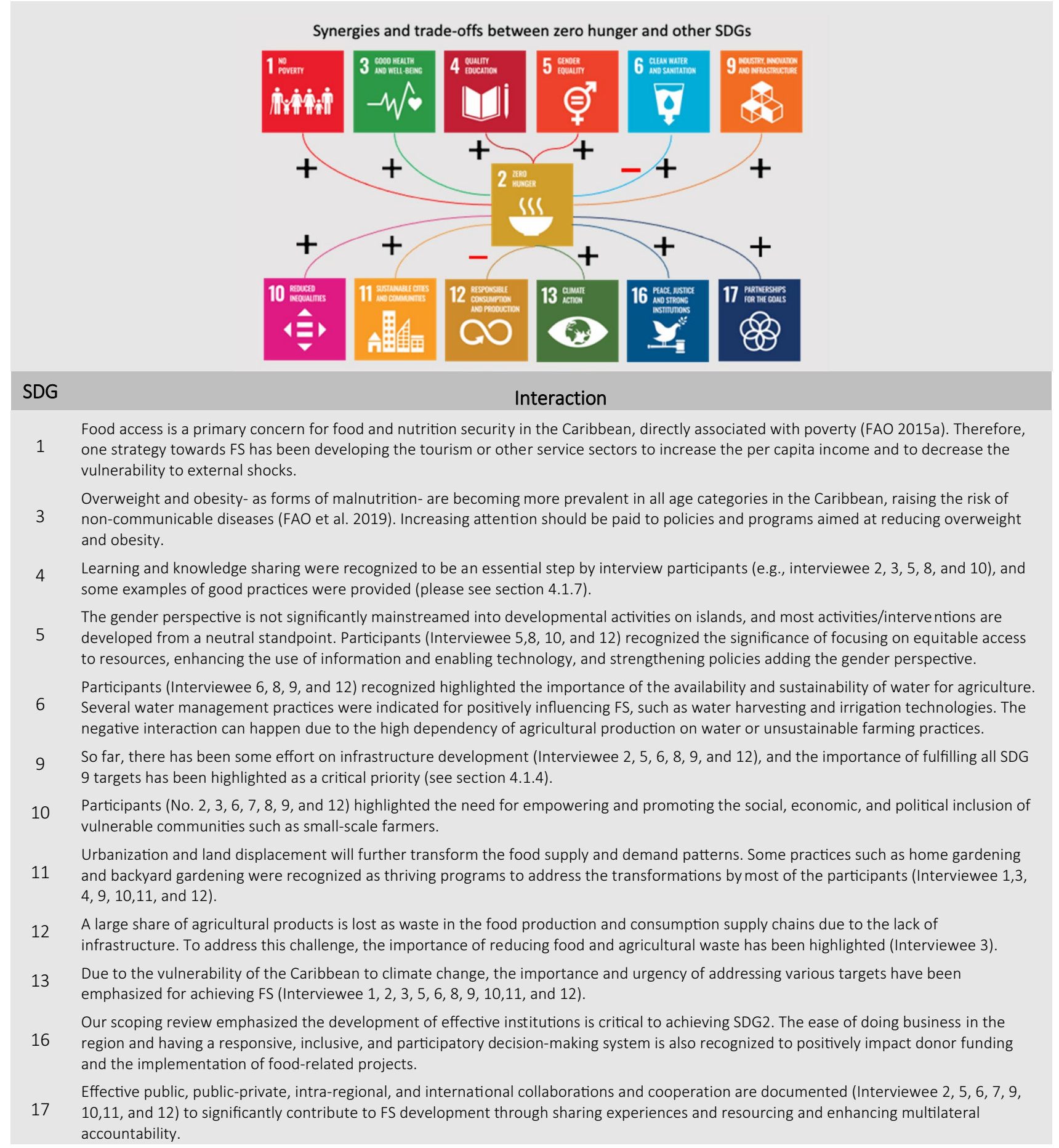

supporting shared rulemaking and knowledge-sharing. As discussed earlier, the causes of food and nutrition insecurity in the region are rooted in barriers at three different system levels: intra-, inter-, and extra-island systems. Forming collaborations between these levels would require strong national and regional policies and different modes of governance. Multi-level governance systems, such as polycentric governance, can be used as a suitable approach to include diverse local, national, and regional centers in the decision-making structure to govern the food system. Polycentricity implies complex governance systems of various decision-making centers with some 
degree of autonomy (Ostrom 2005; Carlisle and Gruby 2019). This governance system can be composed of multiple scattered overlapping decision-making centers with certain degrees of autonomy, competition, and conflict (Carlisle and Gruby 2019), with a higher adaptive capacity (e.g., Sovacool 2011; Silveira and Richards 2013; Pahl-Wostl and Knieper 2014; Carlisle and Gruby 2019). Polycentric arrangements can provide several theoretical benefits, ranging from trust, adaptation, and knowledge sharing to mitigating resource depletion risks (Marshall 2009).

The seven enabling conditions provided by Carlisle and Gruby (2019) need to be fulfilled in the Caribbean to address current barriers and deficiencies. First, decision-making centers should exist at different levels, from local and national to regional, and across various political jurisdictions from parishes to countries. Second, decision-making centers should engage several institutions, ranging from small informal farming communities to various government bodies. Third, the socio-ecological issues need to be mapped, and the extent of the decision-making authorities should overlay onto the spatial boundaries of those issues. Next, applicable rules, norms, incentives, restrictions, and structures should be developed and implemented at local, national, and regional levels. Another necessary condition is to develop formal and informal settings for conflict resolution. Accountability systems would also be necessary for inadequate performance, corruption, or failure. Finally, the SISs would need to implement deliberation and learning mechanisms as procedures to enhance the capability of a governing system. It can be argued that enabling these conditions would ensure addressing the agency dimension of food security and would foster moving towards sustainable food systems.

The paper emphasizes the importance of inter-disciplinary and systemic approaches to food system governance. The significance of formal and informal institutions, as well as the role of state and non-state actors and the nature of multi-level interactions, are discussed as major characteristics of food governance systems. Stakeholder participation and institutional capacity building are recognized as fundamental elements for addressing the obstacles and barriers described in this study. In addition, due to the specific characteristics of food systems in SIS, the governance regimes should have resilience and adaptive capacity. COVID-19 pandemic has even further highlighted the importance of policies that address greater levels of food resilience (Glaros et al. 2021). The direction of decisional and institutional changes should be towards more flexible regulations and institutions that allow for context-specific implementations in different islands.

\section{Conclusion}

Exploring the current FS situation in the Caribbean, five major challenges and barriers were identified: characteristic barriers, governance deficiencies, and institutional constraints compounded by inter-island collaboration barriers and externally imposed impediments. The interview findings on the best practices provided evidence of various arrangements for achieving FS. However, the contributions to some areas, such as developing bottom-up approaches, were rare. Our study highlighted the complex interactions between SDG2 and the other eleven SDGs, among which ten enabling and two constraining interconnections are observed. Given the inherent complexity of food systems in a small island context, a polycentric governance system is recommended as a suitable mechanism. A holistic strategy with a polycentric governance system that considers interactions between SDG2 and other SDGs (by boosting synergies and balancing trade-offs) will ensure capacity enhancement. Better decisions will be ensured if civil societies and those most vulnerable in the food system are included in decision-making. Recognizing multi-stakeholder coalitions and processes within nested, overlapping governance, and jurisdiction layers would help to move towards food security.

Dataset limitations on food and nutrition security indicators for Caribbean SIDS made further quantitative analysis impossible. While data availability may help refine and improve some of our arguments, we believe this would not change our overall conclusion around food insecurity on small islands. This gap would provide future research opportunities for conducting quantitative analyses on synergies, trade-offs, and interactions between SDG2 and other SDGs. This paper provides the first comprehensive analysis of food and nutrition security challenges with implications for food governance systems in an island context.

Supplementary Information The online version contains supplementary material available at https://doi.org/10.1007/s44177-021-00008-8.

Acknowledgements Special thanks to Dr. Robert Kinlocke and Shupa Rahman for their contributions throughout the research. We would like to extend our gratitude to all of the interviewees who participated in this study.

Funding We are grateful for the financial support from the Social Sciences and Humanities Research Council (SSHRC) of Canada that made this research possible; the Insight Development Grant; Award Number: 430-2019-0463.

Data availability All data generated or analyzed during this study are included in this published article [and its supplementary information files]. 


\section{Declarations}

Ethics approval This study has been reviewed and received ethics clearance through a University of Waterloo Research Ethics Committee (ORE 41975).

\section{References}

Ahmed B, Afroz S (1996) The political economy of food and agriculture in the Caribbean. Ian Randle Publishers, Kingston, Jamaica

Arksey H, O'Malley L (2005) Scoping studies: towards a methodological framework. Int J Soc Res Methodol Theory Pract 8:19-32. https://doi.org/10.1080/1364557032000119616

Baldacchino G, Wivel A (2020) Handbook on the politics of small states. Edward Elgar Publishing, Cheltenham. ISBN 978178811 2925

Belton B, Little DC, Zhang W et al (2020) Farming fish in the sea will not nourish the world. Nat Commun 111(11):1-8. https://doi.org/ 10.1038/s41467-020-19679-9

Bonsu NO, Tyreehageman J, Kele J (2020) Beyond agenda 2030: future-oriented mechanisms in localising the sustainable development goals (SDGs). Sustainability 12:9797. https://doi.org/10. 3390/SU12239797

Brown G, Kyttä M (2014) Key issues and research priorities for public participation GIS (PPGIS): a synthesis based on empirical research. Appl Geogr 46:122-136. https://doi.org/10.1016/j. apgeog.2013.11.004

Brown DE (2014) Essays on smallholder farmers in Jamaica: contextspecific evidence for food security policymaking. Theses and Dissertations. 2206, University of Arkansas, Fayetteville

Candel J, Daugbjerg C (2020) Overcoming the dependent variable problem in studying food policy. Food Secur 12:169-178. https:// doi.org/10.1007/S12571-019-00991-2/TABLES/2

Canterbury D (2007) Caribbean agriculture under three regimes: colonialism, nationalism and neoliberalism in Guyana. J Peasant Stud 34:1-28. https://doi.org/10.1080/03066150701311837

CARICOM (2011) Trade and food security (food safety and TBTs). Policy Brief No. 5. Caribbean Community (CARICOM), FAO, Rome, Italy.

Carlisle K, Gruby RL (2019) Polycentric systems of governance: a theoretical model for the commons. Policy Stud J 47:921-946. https://doi.org/10.1111/psj.12212

Clapp J, Moseley WG, Burlingame B, Termine P (2021) The case for a six-dimensional food security framework. Food Policy 106:102164. https://doi.org/10.1016/j.foodpol.2021.102164

Connell J (2015) Food security in the island Pacific: is Micronesia as far away as ever? Reg Environ Chang 15:1299-1311. https://doi. org/10.1007/s10113-014-0696-7

Cook R, Yang Y-H (1974) National food and nutrition policy in the Commonwealth Caribbean. PAHO Bull 8(2):133-42. https://iris. paho.org/handle/10665.2/27127

da Silveira AR, Richards KS (2013) The link between polycentrism and adaptive capacity in river basin governance systems: insights from the River Rhine and the Zhujiang (Pearl River) Basin. Geogr Water Qual 103:319-329. https://doi.org/10.1080/00045608.2013. 754687

Derlagen C, Tas J, Boyce RA et al (2017) Analysis of agricultural policies in Guyana. Inter-American Development Bank (IDB), Washington DC, USA. https://doi.org/10.18235/0000889

Dulal HB, Shah KU, Ahmad N (2009) Social equity considerations in the implementation of Caribbean climate change adaptation policies. Sustainability 1:363-383. https://doi.org/10.3390/su1030363
FAO (2015a) State of food insecurity in the CARICOM Caribbeanmeeting the 2015 hunger targets: taking stock of uneven progress. Food and Agricultural Organization of the United Nations, Bridgetown, Barbados. ISBN 978-92-5-108964-4

FAO (2015b) Regional overview of food insecurity in Latin America and the Caribbean. Food and Agricultural Organization of the United Nations, Rome, Italy. ISBN 978-92-5-108782-4

FAO (2017a) Parliamentary fronts against hunger, and legislative initiatives for the right to adequate food and nutrition. Food and Agriculture Organization of the United Nations, Rome, Italy. ISBN 978-92-5-09984-1

FAO (2017b) The impact of disasters and crises on agriculture and food security. Food and Agriculture Organization of the United Nations, Rome, Italy. ISBN 978-92-5-130359-7

FAO (2019) Food security and nutrition in SIDS implementing the global action programme in Small Island Developing States (SIDS). Food and Agriculture Organization of the United Nations, Rome, Italy

FAO (2021) The state of food security and nutrition in the World (2021) FAO, IFAD, UNICEF. WFP and WHO. Food and Agriculture Organization of the United Nations, Rome, Italy. ISBN 978-92-5-134325-8

FAO, CDB (2019) Study on the state of agriculture in the Caribbean. The Food and Agriculture Organization of the United Nations and the Caribbean Development Bank, Rome, Italy. ISBN 978-92-5-131488-3

FAO, IFAD, UNICEF et al (2019) The state of food security and nutrition in the world-safeguarding against economic slowdowns and downturns. Food and Agriculture Organization of the United Nations, Rome, Italy. ISBN 978-92-5-131570-5

FAO, PAHO (2017) Panaroma of food and nutrition security in Latin American and the Caribbean. Food and Agriculture Organization of the United Nations and the Pan American Health Organization, Santiago de Chile. ISBN 978-92-5-130056-5

Ford JRD (1992) Guyana's food performance in a Caribbean context. Lessons for food security policy. Food Policy 17:326-336. https:// doi.org/10.1016/0306-9192(92)90061-2

Ganpat W, Isaac WAP (2014) Impacts of climate change on food security in Small Island Developing States. IGI Global. https://doi.org/ 10.4018/978-1-4666-6501-9

Glaros A, Alexander C, Koberinski J et al (2021) A systems approach to navigating food security during COVID-19: gaps, opportunities, and policy supports. J Agric Food Syst Community Dev 10:211-223. https://doi.org/10.5304/jafscd.2021.102.051

Grindle MS (1993) Agrarian class structures and state policies: Past, present, and future. Latin Am Res Rev 28:174-87. http://www. jstor.org/stable/2503805

Handa S, King D (1997) Structural adjustment policies, income distribution and poverty: a review of the Jamaican experience. World Dev 25:915-930. https://doi.org/10.1016/S0305-750X(97) 00005-3

Harvey EC (2010) Strategic plan for regional development (SPRD) background study regional agrotourism policy Harvey EC (2010.) Strategic plan for regional development (SPRD). Background study - Regional agritourism policy, IICA

Hawkes C, Thow AM (2008) Implications of the central AmericaDominican republic - free trade agreement for the nutrition transition in Central America. Rev Panam Salud Publica/pan Am J Public Heal 24:345-360. https://doi.org/10.1590/S1020-49892 008001100007

Henry FJ (2012) Food and nutrition research in the Caribbean. West Indian Med J 61:338-350. https://doi.org/10.7727/wimj.2012.149

IMF (2016) Small states' resilience to natural disasters and climate change-role for the IMF. International Monetary Fund Washington, DC 
IMF (2018) Dominican Republic: 2018 Article IV consultation-press release and Staff Report. IMF Staff Ctry Reports 18:1. https://doi. org/10.5089/9781484381243.002

Innerarity F (1996) Program for the analysis of agricultural policies vis-à-vis women food producers in the Andean, the Southern Cone and the Caribbean. Costa Rica, San Jose

Jamaican Ministry of Agriculture and Fisheries and Ministry of Health (2013) Food and nutrition security policy-Government of Jamaica. Ministry of Agriculture and Fisheries and Ministry of Health, Jamaica

Kendall P, Petracco M (2009) The current state and future of Caribbean agriculture. J Sustain Agric 33:780-797. https://doi.org/10.1080/ 10440040903221409

Klennert K (2005) Achieving food and nutrition security: actions to meet the global challenge. Internationale Weiterbildung und Entwicklung gGmbH, Bonn, Germany. ISBN: $\mathbf{9 7 8 3 9 3 7 2 3 5 7 1 4}$

Lang T (1999) (1999) The complexities of globalization: the UK as a case study of tensions within the food system and the challenge to food policy. Agric Hum Values 162(16):169-185. https://doi. org/10.1023/A:1007542605470

Lang T, Barling D (2012) Food security and food sustainability: reformulating the debate. Geogr J 178:313-326. https://doi.org/10. 1111/J.1475-4959.2012.00480.X

Lang T, Heasman M (2015) Food wars: the global battle for mouths, minds and markets. Routledge, Milton Park. ISBN $\mathbf{9 7 8 0 3 6 7 2 4 0 6 1 5}$

Lang T, Barling D, Caraher M (2009) Food policy: integrating health, environment and society. Oxford University Press, Oxford. ISBN: $\mathbf{9 7 8 0 1 9 8 5 6 7 8 8 2}$

Lowitt K, Saint VA, Keddy CSM et al (2016) Challenges and opportunities for more integrated regional food security policy in the Caribbean community. Reg Stud Reg Sci 3:368-378. https://doi. org/10.1080/21681376.2016.1209983

Marshall GR (2009) Polycentricity, reciprocity, and farmer adoption of conservation practices under community-based governance. Ecol Econ 68:1507-1520. https://doi.org/10.1016/J.ECOLECON.2008. 10.008

Mays N, Roberts E, Popay J (2001) Synthesising research evidenceResearch Portal I Lancaster University. In: Pauline A, Nick B, Aileen $\mathrm{C}$ et al (eds) Studying the organisation and delivery of health services. Research methods. Routledge, pp 188-220. ISBN $\mathbf{9 7 8 0 4 1 5 2 5 7 6 3 3}$

McElroy JL, De Albuquerque K (1990) Sustainable small-scale agriculture in small Caribbean Islands. Soc Nat Resour 3:109-129. https://doi.org/10.1080/08941929009380712

Mcpherson JP (2018) National food security in Cuba: by what means? Master of Arts Thesis. Dalhousie University Halifax, Nova Scotia. http://hdl.handle.net/10222/74918

Molina Barrera V, Mejicano Robles G, Alfaro Villatoro N et al (2018) Intervenciones de Fomento al Bienestar Nutricional en América Latina y el Caribe: oportunidades para fortalecer las políticas y programas de alimentación y nutrición. Rev Esp Nutr Comunitaria 24:153-161https://doi.org/10.14642/RENC.2018.24.4.5263

Ostrom E (2005) Understanding institutional diversity. Princeton University Press, Princeton, USA. ISBN: 9780691122380

Pahl-Wostl C, Knieper C (2014) The capacity of water governance to deal with the climate change adaptation challenge: using fuzzy set qualitative comparative analysis to distinguish between polycentric, fragmented and centralized regimes. Glob Environ Chang 29:139-154. https://doi.org/10.1016/J.GLOENVCHA.2014.09. 003

Pemberton CA, Harris EL (1988) Determining the beneficiaries of cheap-food policies in Trinidad and Tobago. https://archive.unu. edu/unupress/food/8F104e/8F104E0b.htm

Pittman J, Tam JC, Epstein G et al (2020) Governing offshore fish aggregating devices in the Eastern Caribbean: exploring trade-offs using a qualitative network model. Ambio 49:2038-2051. https:// doi.org/10.1007/S13280-020-01327-7/TABLES/7

Pollard SK, Graham DH (1985) the performance of the food-producing sector in Jamaica, 1962-1979: a policy analysis. Econ Dev Cult Change 33:731-754. https://doi.org/10.1086/451492

Rahman S, Singh SJ, Mccordic C (2022) Can the Caribbean localize its food system? Evidence from biomass flow accounting. J Ind Ecol

Renwick S (2013) Prioritisation of food security by decision makers in the Caribbean, A study of three Caribbean territories: Trinidad and Tobago, Belize and Barbados. In: 30th West Indies agricultural economics conference. 30th June - 6th July, 2013. The Caribbean Agro-Economic Society (CAES), Port of Spain, Trinidad. ISBN: 978-976-634-013-1

Sachs J, Massa I, Marinescu S, Lafortune G (2021) The decade of action and small island developing states: measuring and addressing SIDS ' vulnerabilities to accelerate SDG progress. Sustainable Development Solutions Network. https://irp.cdn-website.com/ be6d1d56/files/uploaded/WP_MVI_Sachs\%20Massa\%20Mar inescu\%20Lafortune_FINAL_cVeeBVmKSKyYYS6OyiiH.pdf

Saint Ville AS, Hickey GM, Phillip LE (2017a) Institutional analysis of food and agriculture policy in the Caribbean: the case of Saint Lucia. J Rural Stud 51:198-210. https://doi.org/10.1016/j.jrurs tud.2017.03.004

Saint Ville AS, Hickey GM, Phillip LE (2017b) How do stakeholder interactions influence national food security policy in the Caribbean? The case of Saint Lucia. Food Policy 68:53-64. https://doi. org/10.1016/j.foodpol.2017.01.002

Saint Ville AS, Hickey GM, Phillip LE (2017c) How do stakeholder interactions influence national food security policy in the Caribbean? The case of Saint Lucia. Food Policy 68:53-64. https://doi. org/10.1016/j.foodpol.2017.01.002

Sala E, Mayorga J, Bradley D et al (2021) (2021) Protecting the global ocean for biodiversity, food and climate. Nat 5927854(592):397402. https://doi.org/10.1038/s41586-021-03371-z

Shik O, Boyce R, De Salvo CP (2017) Analysis of agricultural policies in Jamaica. Inter American Development Bank, Washington, DC, USA

Singh RH, Rankine LB, Seepersad G (2005) The caricom regional transformation programme for agriculture-a review of agricultural policies: case study of Barbados. St. Augustine, Trinidad

Slack L (2014) The post-2015 global agenda-a role for local government. Commonw J Local Gov. https://doi.org/10.5130/cjlg.v0i0. 4069

Sovacool BK (2011) An international comparison of four polycentric approaches to climate and energy governance. Energy Policy 39:3832-3844. https://doi.org/10.1016/J.ENPOL.2011.04.014

The Joanna Briggs Institute (2015) The Joanna Briggs Institute reviewers' manual. Methodology for JBI scoping reviews. The Joanna Briggs Institute, Adelaide, Australia. https://nursing.lsuhsc.edu/ JBI/docs/ReviewersManuals/Scoping-.pdf

The World Bank (2018) World Bank Provides US\$65 million for Dominica's Post-Maria Reconstruction. World Bank. https://www.world bank.org/en/news/press-release/2018/04/13/world-bank-providesus65-million-for-dominicas-post-maria-reconstruction

Thomas LR, Clavelle T, Klinger DH, Lester SE (2019) The ecological and economic potential for offshore mariculture in the Caribbean. Nat Sustain 21(2):62-70. https://doi.org/10.1038/ s41893-018-0205-y

Thompson MS (2019) Still searching for (food) sovereignty: why are radical discourses only partially mobilised in the independent Anglo-Caribbean? Geoforum 101:90-99. https://doi.org/10. 1016/j.geoforum.2019.02.028

Tiedemann J, Piatkov V, Prihardini D et al (2021) Meeting the sustainable development goals in small developing states with climate vulnerabilities: cost and financing. International Monetary Fund. https://www.imf.org/en/Publications/WP/Issues/2021/03/05/Meeti 
ng-the-Sustainable-Development-Goals-in-Small-DevelopingStates-with-Climate-50098

Tirado MC, Galicia L, Husby HM et al (2016) Mapping of nutrition and sectoral policies addressing malnutrition in Latin America. Pan Am J Public Health 40:114-123

Tricco AC, Lillie E, Zarin W et al (2018) PRISMA extension for scoping reviews (PRISMA-ScR): checklist and explanation. Ann Intern Med 169:467-473. https://doi.org/10.7326/M18-0850/ SUPPL_FILE/M18-0850_SUPPLEMENT.PDF

Trotman A, Gordon RM, Hutchinson SD et al (2009) Policy responses to GEC impacts on food availability and affordability in the Caribbean community. Environ Sci Policy 12:529-541. https://doi.org/ 10.1016/j.envsci.2009.02.001

UCLG (2019) 3rd Local and Regional Governments Report, Towards the Localization of the SDGs, launched at 2019 HLPF I UCLG. In: United Cities Local Gov. https://www.uclg.org/en/media/news/ 3rd-local-and-regional-governments-report-towards-localizationsdgs-launched-2019-hlpf. Accessed 12 Dec 2021

UN (2015) Transforming our world: the 2030 Agenda for Sustainable Development I Department of Economic and Social Affairs, The United Nations, New York

UN-OHRLLS (2011) Small island developing states: small islands big (ger) stakes. Office of the High Representative for the Least Developed Countries, Landlocked Developing Countries and Small Island Developing States, New York, USA

USDA (2014) Caribbean basin exporter guide. GAIN Report Number: CB1401. USDA Foreign Agricultural Service, Wasington, DC, USA

Wilson M (2016) Food and nutrition security policies in the Caribbean: challenging the corporate food regime? Geoforum 73:60-69. https://doi.org/10.1016/j.geoforum.2015.05.005 